Gandhi Pullagura, Babji Alapati, Mahendra Babu Kantipudi / IOSR Journal of Engineering (IOSRJEN)

www.iosrjen.org

ISSN : 2250-3021

Vol. 2 Issue 1, Jan.2012, pp. 001-006

\title{
Effect of hydrogen enrichment on the combustion characteristics of a bio- fuel diesel engine
}

\author{
Gandhi Pullagura ${ }^{1}$, Babji Alapati ${ }^{2}$, Mahendra Babu Kantipudi ${ }^{3}$, Prakash $\mathbf{R}^{4}$ \\ (Department of Mechanical Engineering, Regency Institute of technology, Yanam, / Pondicherry University, India) \\ '(Department of Mechanical Engineering, Regency Institute of technology, Yanam,/ Pondicherry University , India) \\ ${ }^{3}$ (Department of Mechanical Engineering, Regency Institute of technology, Yanam, / Pondicherry University, India) \\ ${ }^{4}$ (Department of Mechanical Engineering, National institute of technology, Rourkela, / NITR, India)
}

\begin{abstract}
Esters of vegetable oil and bio oil produced by pyrolysis of various biomass resources have greater scope as alternative fuels for the future in power and transportation sectors. In this experiments were conducted to evaluate the combustion parameters of a compression ignition engine fuelled with biodiesel-bio oil emulsion and hydrogen on a dual fuel mode. Hydrogen was inducted in small quantities in a diesel engine whereas an emulsion of bio-oil and methyl ester of karanja was injected into the cylinder as a main fuel. The impact of dual fuel mode on rate of pressure rise, peak pressure, ignition delay and heat release rate of the engine were studied. The results were compared with diesel fuel operation and presented in this paper.
\end{abstract}

keywords - bio-diesel, biomass, bio-oil, emulsion, hydrogen enrichment, pyrolysis.

\section{INTRODUCTION}

Diesel engines are the most popular prime movers in transportation and agriculture sector, because of their high brake thermal efficiency and durability compared to gasoline engines. Increasing demand of diesel engine results in a huge fuel consumption. As a result of this there is a scarcity of fuel and hike in the fuel price. Besides, emissions from engine exhaust also increases. Therefore, a better and suitable alternative fuels are required to replace the diesel fuel and that is the need of the day. The search for an alternative fuel, which promises a harmonious correlation with sustainable development, energy conservation, management, efficiency, and environmental preservation, has become highly pronounced in the present context. Biomass is organic matter produced by plant, both terrestrial (those grown on land) and aquatic (those grown in water) and their derivatives. It includes forest crops and residues, crops grown especially for their energy content on 'energy farms' and animal manure. Biomass is considered as a renewable energy source because plant life renews itself every year. Biomass can be converted into useful energy by pyrolysis process.
Pyrolysis of biomass yields solid, liquid and gaseous products like char, pyrolytic oil and pyrogas [1].

Experiments have been carried out to determine the feasibility of flash pyrolysis oil in diesel engines [2-4]. Injection system failure and faster erosion on steel components in the engine were noticed from the results. Major problem with the wood pyrolysis oil is its miscibility with diesel fuel. The problem of immiscibility can be rectified by up gradation of pyrolysis oil by emulsification process [5]. Emulsion is one of the techniques used while a fuel has to be mixed with another fuel of hydroscopic nature. Stable wood pyrolysis oil emulsions were prepared using two surfactants namely hypermer and CANMET [6]. It was observed that the viscosity was found to reduce when the emulsion was prepared with a maximum of $20 \%$ pyrolysis oil. Emulsion prepared with an addition of Tween 20 surfactant $2 \%$ by volume with six different percentages of water as fuels were tested in a diesel engine [7]. It was observed from the results that the $5 \%$ by volume of water diesel emulsion gave an optimum brake power and a brake thermal efficiency compared with the other water diesel emulsions. Since vegetable oils usually produce high smoke emissions from diesel engines, dual fuel operation can be adopted as a method for improving their performance.

Literatures indicate that dual fuel operation is useful to reduce smoke and increase the thermal efficiency of the diesel engines [8-9]. In the absence of carbon, sulfur, and lead, the exhaust emissions from hydrogen-operated engine are free from host of noxious pollutants such as carbon monoxide, carbon dioxide and other greenhouse gases, hydrocarbons, sulfur oxides, smoke, lead or other toxic metals, sulfuric acid, ozone and other oxidants, benzene and other carcinogenic compounds and formaldehydes [10]. Dual fuel operation of a diesel engine was studied by many researchers using different pilot fuels such as diesel, jatropha, mahua, rubber seed oil and their methyl esters and inducted fuels such as hydrogen, CNG and biogas[8-12]. The reasons for applying hydrogen as addition fuel are to increase the $\mathrm{H} / \mathrm{C}$ ratio and to decrease the heterogeneity of the fuel spray. The high diffusivity of 


\section{Gandhi Pullagura, Babji Alapati, Mahendra Babu Kantipudi / IOSR Journal of Engineering (IOSRJEN) \\ www.iosrjen.org \\ ISSN : 2250-3021}

Vol. 2 Issue 1, Jan.2012, pp. 001-006

hydrogen which makes the combustible mixture better premixed with air and more uniform. It could also reduce the combustion duration due to hydrogen's high speed of flame propagation in relation to other fuels [13].Therefore an attempt was made to investigate the combustion characteristics of a single cylinder, four stroke, air cooled, direct injection diesel engine running on dual fuel mode. An emulsion of wood pyrolysis oil and methyl ester of karanja was used as primary fuel in the engine, whereas, hydrogen was admitted into the diesel engine at $21 \mathrm{pm}$ and $4 \mathrm{lpm}$ in the suction along with the air.

\section{METHODS AND MATERIALS}

\subsection{Production of wood pyrolysis oil}

In the present investigation, pyrolysis oil from waste wood was obtained by vacuum pyrolysis process. The production process and the characteristics of wood pyrolysis oil were studied by Prakash et al [14].

\subsection{Methyl ester of karanja oil}

Karanja methyl ester used in this investigation was obtained from the transesterification process of karanja oil. Methyl ester of karanja oil is produced by the Transesterification process. Esterification of karanja oil is composed of heating of oil, addition of $\mathrm{KOH}$ and methyl alcohol, stirring of mixture, separation of glycerol, washing with distilled water and heating for removal of water.

\subsection{Properties of WPO and MEK compared with diesel}

The properties of wood pyrolysis oil (WPO) are compared with diesel fuel and karanja methyl ester (MEK) is given in Table 1.

Table 1: Properties of Fuels Compared

\begin{tabular}{|l|c|c|c|c|}
\hline \multicolumn{1}{|c|}{ Properties } & ASTMStandard & Diesel & MEK & WPO \\
\hline Specific gravity at $15^{\circ} \mathrm{C}$ & ASTM D 4052 & 0.83 & 0.88 & 1.1560 \\
\hline $\begin{array}{l}\text { Net calorific } \\
\text { value[MJ } / \mathrm{kg}]\end{array}$ & ASTM D 4809 & 43.8 & 38.41 & 20.58 \\
\hline Flash point $\left[{ }^{\circ} \mathrm{C}\right]$ & ASTM D 93 & 50 & 230 & 98 \\
\hline Fire point $\left[{ }^{\circ} \mathrm{C}\right]$ & ASTM D 93 & 56 & 258 & 108 \\
\hline Pour point $\left[{ }^{\circ} \mathrm{C}\right]$ & ASTM D 97 & 30 & -3 & 2 \\
\hline Carbon residue[\%] & D 2500-05 & 0.1 & 0.71 & 12.85 \\
\hline $\begin{array}{l}\text { Kinematic viscosity } \\
\text { at 40 }{ }^{\circ} \mathrm{C}[\mathrm{cSt}]\end{array}$ & ASTM D 445 & 4.59 & 20.5 & 52.3 \\
\hline Cetane number & ASTM D 613 & 50 & 57.6 & - \\
\hline
\end{tabular}

The calorific value and cetane number of MEK are comparable to diesel but the density is higher, whereas, the calorific value is lower for WPO. In general, if the spray of a fuel with a high-density, penetration will be deeper. The spray will not also diverge as it comes out of the nozzle. Since the viscosity of KME higher than diesel this can lead to poor atomization and mixture formation with air. Carbon residue of WPO is also high which can lead to high smoke levels and injector coking. Coking of the injector leads to poor fuel atomization [15]. The flash point of WPO and KME are higher than diesel; hence it is safe to use it in the engine.

\subsection{Emulsification of WPO}

In this investigation, the water in oil emulsion was prepared by adding the surfactant Span-20 having HLB number 8.6 to emulsify the wood pyrolysis oil with karanja methyl ester. WPO fuel emulsion was prepared from wood pyrolysis oil $10 \%$ and karanja methyl ester $90 \%$ with the addition of surfactant Span-20 1\% by volume. The resultant mixture was stirred vigorously for about 30 minutes. The emulsion produced was observed visually by about eight hours and found that the emulsion made with $10 \%$ WPO was stable.

\section{EXPERIMENTAL PROCEDURE}

The engine used in the present work is a single cylinder, four strokes, air cooled, direct injection, diesel engine. The photographic view of the experimental setup is shown in Fig. 1 and the engine specification is given in Table 2. Initially the engine was operated with neat diesel and the base line readings were obtained for emission and combustion. Then the engine was allowed to run with the WPO-MEK emulsion.

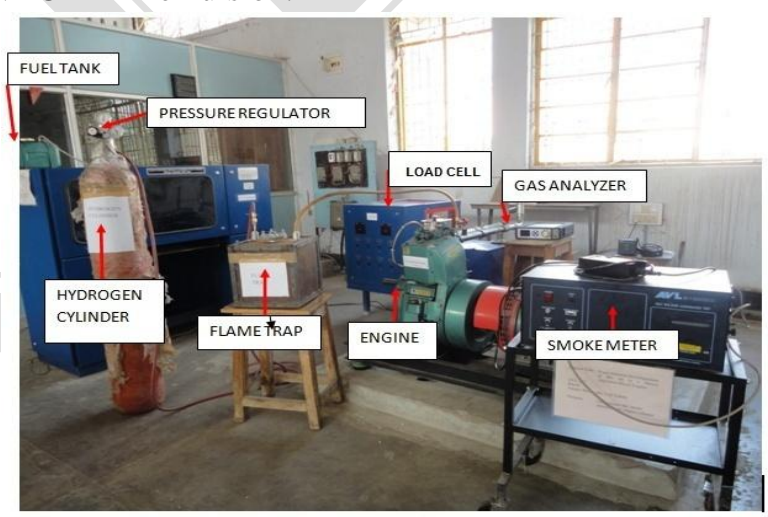

Fig.1 Photographic view of the engine experimental set up

Hydrogen was supplied in the intake of the engine at a pressure of 1.25 bar from a high pressure cylinder (150 bar) by using hydrogen pressure regulator. The flow rate of hydrogen to the engine was measured by a gas flow meter in $\mathrm{lpm}$. The hydrogen was passed through a non return valve (NRV), which prevents the reverse flow of hydrogen into the system. Hydrogen was allowed to pass through the flame trap used to suppress the flashback if any in the intake manifold. The flame trap was made of mild steel iron to suppress the flame and water to put off the flame. The hydrogen from the flame trap was sent into the inlet manifold to mix it with the air. The process of mixing the inlet air and fuel is called as enrichment. Thus by keeping the flow of hydrogen as $21 \mathrm{pm}$ and $4 \mathrm{lpm}$, the combustion characteristics of bio-fueled diesel engine was studied. The emulsion on volume basis was allowed from the fuel tank and then injected into the cylinder. The combustion analysis was performed in the experiment with the help of Kistler pressure transducer fitted on the cylinder head of 


\section{Gandhi Pullagura, Babji Alapati, Mahendra Babu Kantipudi / IOSR Journal of Engineering (IOSRJEN) \\ www.iosrjen.org \\ ISSN : 2250-3021}

Vol. 2 Issue 1, Jan.2012, pp. 001-006

the engine and crank angle encoder fitted to the output shaft.

Table 2: Test engine specification

\begin{tabular}{|l|c|}
\hline Make/Model & Kirloskar TAF 1 \\
\hline Brake power, kW & 4.4 \\
\hline Rated speed, rpm & 1500 \\
\hline Bore [mm] & 80 \\
\hline Stroke [mm] & 110 \\
\hline Compression Ratio & $17.5: 1$ \\
\hline Cooling System & Air cooling \\
\hline Injection timing, ${ }^{\circ}$ CA & $23^{\circ}$ bTDC \\
\hline Nozzle opening pressure, bar & 200 \\
\hline
\end{tabular}

\section{RESULTS AND DISCUSSION}

\subsection{Combustion parameters}

1) Crank angle with pressure: Fig.2 shows the variation of cylinder pressure with crank angle at full load. The point where the pressure curves suddenly rises also indicates the start of combustion [17]. The advantage in attaining peak pressure is due to high rate of pressure rise while inducting hydrogen compared to that of diesel operation [16]. The sudden change in slope in the pressure trace results from the sudden increase in the rate of pressure-rise which indicates ignition. It is observed from the figure that at full load, the combustion starts earlier in the case of WPO-MEK by $1{ }^{\circ} \mathrm{CA}$ and it is further advanced by $1.45^{\circ} \mathrm{CA}$ and $1.91^{\circ} \mathrm{CA}$ for $2 \mathrm{lpm}$ and $4 \mathrm{lpm}$ respectively for hydrogen enrichment in the air. This may be due the oxygen availability in the karanja methyl ester which may initiate the combustion in little earlier than that of diesel and WPO-MEK emulsion.

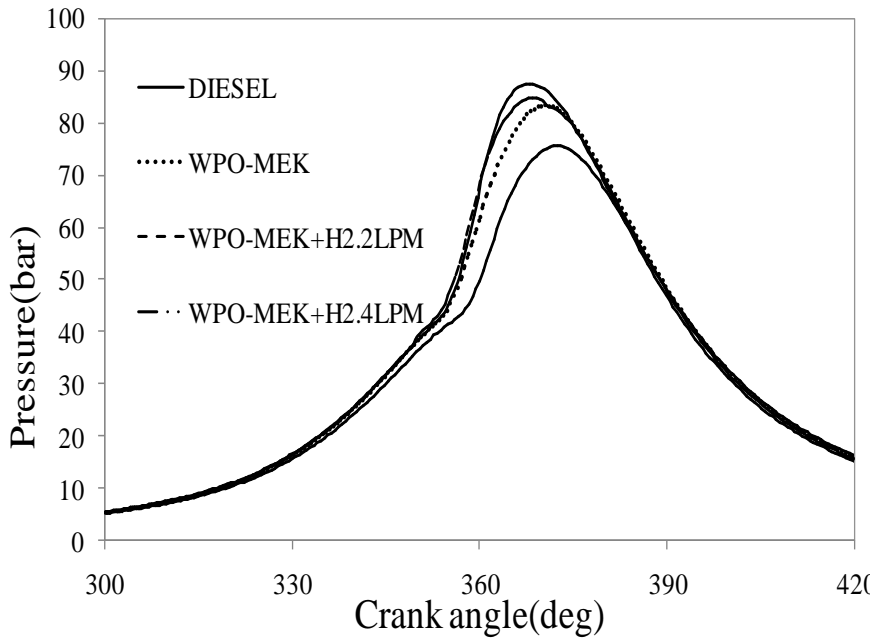

Fig. 2 Variation of the crank angle with pressure

2) Ignition delay: The variation of ignition delay with brake power is given in Fig.3.

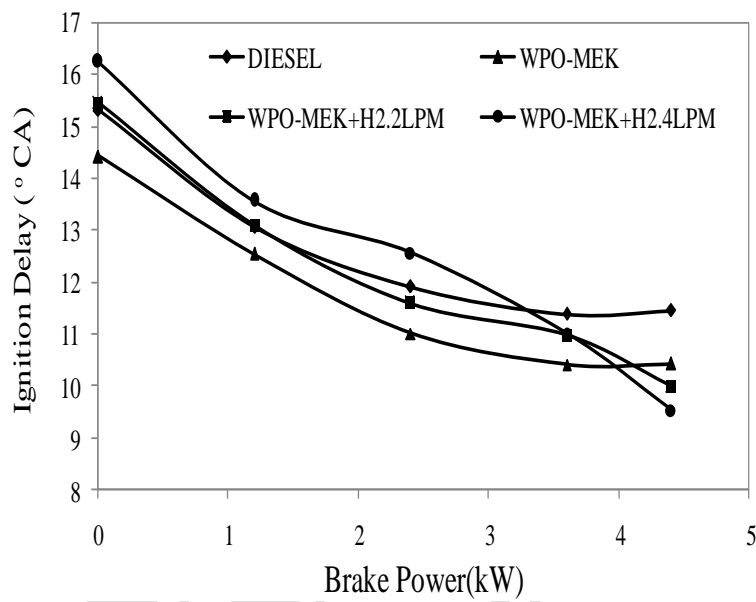

.Fig. 3 Variation of the ignition delay with brake power

The ignition delay is the time difference between the start of injection and ignition in compression ignition engines. At lower loads, the ignition delay of injected pilot fuel (WPO-MEK) is longer than diesel fuel operation with hydrogen enrichment. This may be due to the reduction in the oxygen concentration resulting from the hydrogen fuel substitution in the air [18]. Also due to high self ignition temperature of hydrogen, all the hydrogen enriched fuel shows more ignition delay [19]. But at full loads, due the availability of heat inside the cylinder the ignition delay decreases considerably.

3) Peak pressure: It mainly depends on the combustion rate in the initial stages, which is influenced by the fuel taking part in uncontrolled heat release phase [20]. The variation of the cylinder peak pressure with hydrogen enrichment at full load is shown in Fig.4.The peak pressure with the WPO-MEK is higher due to the improvement in preparation of air fuel mixture as a result of low fuel viscosity 


\section{Gandhi Pullagura, Babji Alapati, Mahendra Babu Kantipudi / IOSR Journal of Engineering (IOSRJEN) \\ www.iosrjen.org \\ ISSN : 2250-3021}

Vol. 2 Issue 1, Jan.2012, pp. 001-006

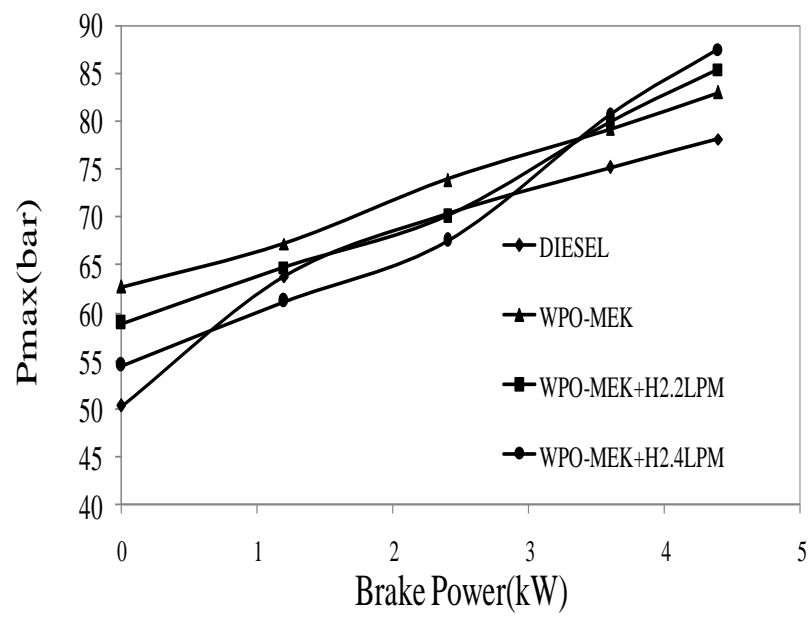

Fig. 4 Variation of the cylinder peak pressure with brake power

It is found that the peak pressure increases with increase in hydrogen addition. At full load the peak pressure is 78.17 bar and 83 bar for diesel and WPO-MEK respectively. The peak pressure of WPO-MEK is 85.45 bar and 87.53 bar with hydrogen enrichment of $21 \mathrm{pm}$ and $41 \mathrm{pm}$ respectively. The presence of hydrogen makes WPO-MEK to burn rapidly and increases the peak pressure.

4) Heat release rate: The variation of maximum heat release rate with crank angle is shown in Fig.5.

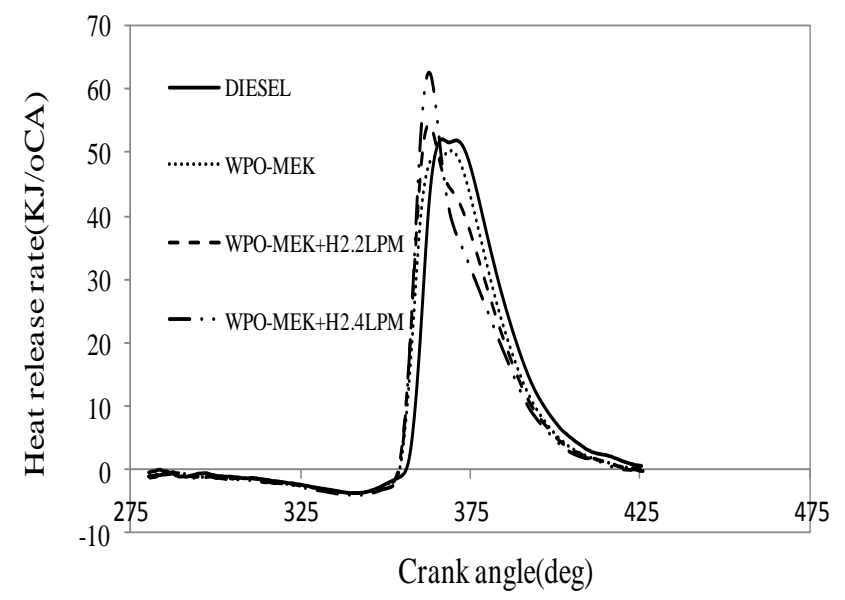

Fig. 5 Variation of heat release rate with crank angle

It is observed from the figure that the hydrogen induction shows a brief premixed combustion phase, followed by slightly higher diffusion combustion phase than diesel fuel [20]. The maximum heat release rate for diesel is $52 \mathrm{~J} / \mathrm{deg}$ CA whereas, for WPO at full load the maximum heat release rate is $50.18 \mathrm{~J} / \mathrm{deg} \mathrm{CA}$. The heat release rate for WPO-MEK with hydrogen flow rate at $2 \mathrm{lpm}$ is $54.5 \mathrm{~J} / \mathrm{deg}$ $\mathrm{CA}$ and with $4 \mathrm{lpm}$ flow rate of hydrogen the heat release rate is $62.47 \mathrm{~J} / \mathrm{deg} \mathrm{CA}$. In dual fuel operation, the fuel accumulated during the ignition delay period burns with the hydrogen entrained along with it and leads to high heat release rates as compared to WPO-MEK operation. The heat release rate in the dual fuel mode becomes very high, as the amount of hydrogen mass is increased. The reason may be that while inducting hydrogen higher heat release rate is achieved in advance due to instantaneous combustion of gaseous fuel [21].

\subsection{Emission parameters}

1) Hydro carbon emissions: The variation of $\mathrm{HC}$ emissions with the brake power is shown in Fig.6. The HC emissions of WPO-MEK are lower compared to diesel and it is further lowered for hydrogen inducted at $2 \mathrm{lpm}$ and 4 lpm [22]. Since hydrogen has no carbon, burning of hydrogen along with

WPO-MEK emulsion leads to reduced hydrocarbon level. And also because of high cylinder temperature the carbon particles, present in lubricating oil and main fuel, gets oxidises and converted into $\mathrm{CO}_{2}$.

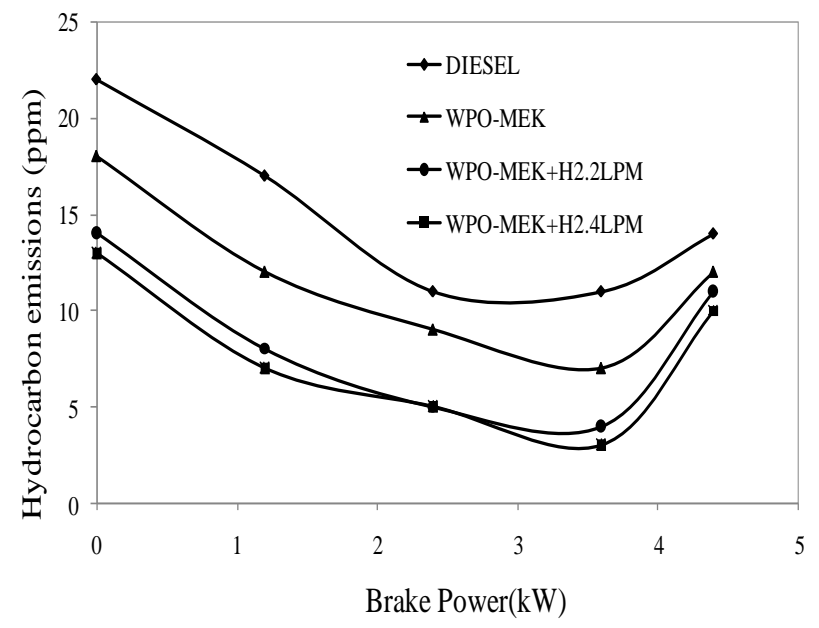

Fig. 6 Variation of hydrocarbon emission with brake power

2) Carbon monoxide emissions: The variation of the carbon monoxide with hydrogen enrichment at all loads is shown in Fig.7. It is found that the carbon monoxide emissions of WPO-MEK are lower than diesel operation and it is increased with increase in hydrogen concentration. The induction of hydrogen reduces the mass of air inducted and leads to higher $\mathrm{CO}$ emissions due to oxygen deficiency [23]. 


\section{Gandhi Pullagura, Babji Alapati, Mahendra Babu Kantipudi / IOSR Journal of Engineering (IOSRJEN) \\ $w w w$.iosrjen.org

Vol. 2 Issue 1, Jan.2012, pp. 001-006

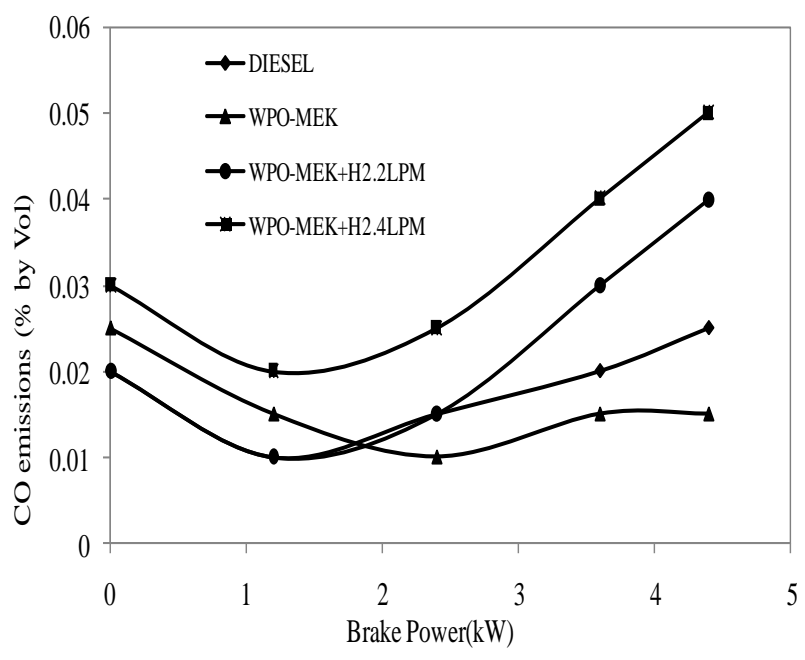

Fig. 7 Variation of the carbon monoxide with brake power

3) NO and smoke emissions: The variations of NO and smoke emissions with brake power is shown in Fig.8. The formation of oxides of nitrogen is due to the peak combustion temperature, oxygen concentration in the combustion chamber and the residence time of high temperature gas in the cylinder [25]. The NO emission values are $318 \mathrm{ppm}$ and $481 \mathrm{ppm}$ with diesel and WPOMEK operation respectively at full load. The values are $523 \mathrm{ppm}$ and $550 \mathrm{ppm}$ with $2 \mathrm{lpm}$ and 4lpm hydrogen enrichment respectively at full load. Hence, there is $51.2 \%$, $64.4 \%$ and $72 \%$ increase in NO emissions for WPO-MEK, WPO-MEK with 2lpm, 4lpm of hydrogen induction respectively. Oxygen concentration in WPO-MEK may be reason for increased NO emissions. The enhanced combustion rate increases the cycle temperature leads to higher NO emissions when hydrogen is inducted in small quantities [9].

With WPO-MEK operation smoke emission is higher at all the loads due to poor atomization of the fuel. The smoke density is $32.8 \%$ with WPO-MEK at peak power output. However, there is a significant reduction of smoke emission in dual fuel operation. It is reduced by $26.2 \%$ and $31 \%$ when operated along with hydrogen quantities $21 \mathrm{pm}$ and $41 \mathrm{pm}$ respectively. The introduction of hydrogen reduces the quantity of injected fuel and lowers the smoke level at all power outputs. Further, it can be observed that the inducted hydrogen forms a homogeneous mixture that burns more rapidly and the overall mixture contains less

carbon from which smoke can form [8].

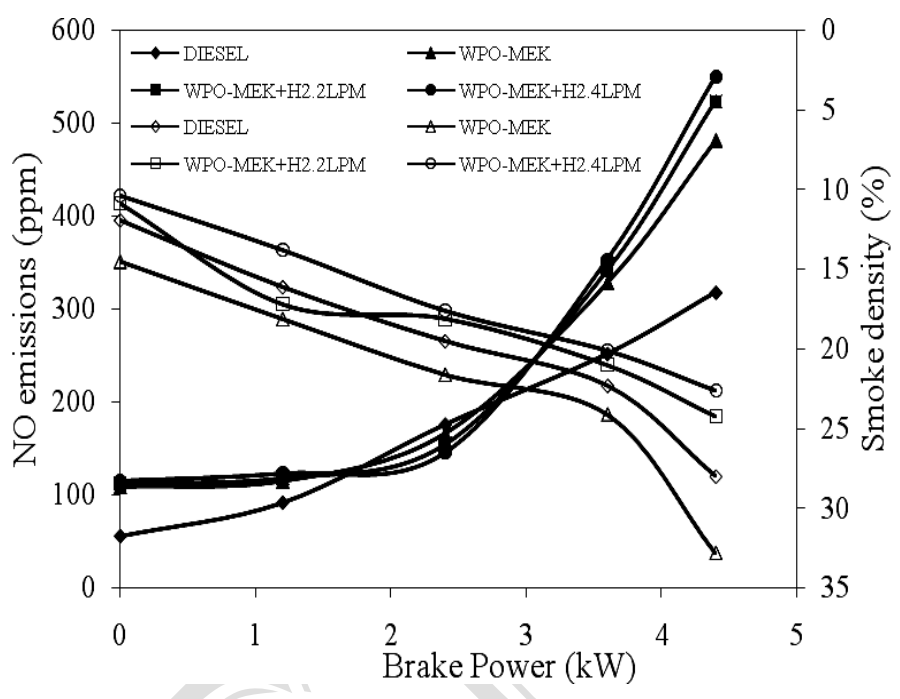

Fig. 8 Variation of the NO and smoke emissions with brake power

\section{CONCLUSIONS}

From the experimental results the following conclusions were made:

- The combustion starts earlier in the case of WPOMEK and it is further advanced when there is hydrogen enrichment in the air.

- At lower loads it is found that the ignition delay of injected pilot fuel (WPO-MEK) exhibits longer than diesel fuel operation with hydrogen enrichment and at full loads, the ignition delay decreases considerably.

- The peak pressure with the WPO-MEK is higher due to the improvement in preparation of air fuel mixture as a result of low fuel viscosity and the presence of hydrogen makes WPO-MEK to burn rapidly and increases the peak pressure.

- In dual fuel operation, the fuel accumulated during the ignition delay period burns with the hydrogen entrained along with it and leads to high heat release rates as compared to WPO-MEK operation.

- $\quad \mathrm{HC}$ emissions of WPO-MEK are lower compared to diesel and it is further lowered when hydrogen was added in $2 \mathrm{lpm}$ and $4 \mathrm{lpm}$.

- It is found that the carbon monoxide emissions of WPO-MEK are lower than diesel operation and it is increased with increase in hydrogen concentration.

- $\quad$ There is $51.2 \%, 64.4 \%$ and $72 \%$ increase in NO emissions for WPO-MEK, WPO-MEK with 2lpm, 4lpm of hydrogen induction respectively.

- The smoke density is $32.8 \%$ with WPO-MEK at peak power output. It is reduced by $26.2 \%$ and $31 \%$ when operated along with hydrogen quantities $2 \mathrm{lpm}$ and $4 \mathrm{lpm}$ respectively. 


\section{Gandhi Pullagura, Babji Alapati, Mahendra Babu Kantipudi / IOSR Journal of Engineering (IOSRJEN) www.iosrjen.org ISSN : 2250-3021}

Vol. 2 Issue 1, Jan.2012, pp. 001-006

\section{REFERENCES}

[1] David Chiaramonti, Anja Oasmaa and Yrjo Solantausta, "Power generation using fast pyrolysis Liquids from biomass", Renewable and Sustainable Energy Reviews,Vol.11, pp 1056-1086, 2007.

[2] Yrjo Solantausta, Nils Olof Nylund,MartenWesterholm Tiina Koljonen and Anja Oasmaa, "Wood- Pyrolysis oil as fuel in a diesel-power plant", Bioresource Technology 46, 1993, pp 177-188.

[3] S.Frigo, R.Gentilli. L.Tognotti and S. Zanforlin, G. Benelli, "Feasibility of Using Wood Flash-Pyrolysis Oil in Diesel Engines", SAE 982529.

[4] C. Bertoli, J.D. Alessio, N. Del Giacomo, M. Lazzaro, P.Massoli and V.Moccia, "Running Light-Duty DI Diesel Engines with Wood Pyrolysis Oil”, SAE 2000-01- 2975.

[5] Zhang Qi, Chang Jie, Wang Tiejun and $\mathrm{Xu}$ Ying, "Review of biomass pyrolysis oil properties and upgrading research", Energy Conversion and Management 48, 2007, pp 87-92.

[6] Michio Ikura, maria Stanciulescu and Ed Hogan, "Emulsification of biomass derived bio-oil in diesel fuel", Biomass and bioenergy Vol 24, pp.221-232, 2003.

[7] A. Alahmer, J. Yamin, A. Sakhrieh and M.A. Hamdan, "Engine Performance using emulsified diesel fuel” , GCREEDER 2009, Amman - Jordan, March 31st April $2^{\text {nd }} 2009$.

[8] M. Senthil Kumar, A.Ramesh and B.Nagalingam," use of hydrogen to enhance the performance of a vegetable oil fuelled compression ignition engine," Int. J. Hydrogen Energy 28, pp 1143-1154, 2003.

[9] V.Edwin Geo, G. Nagarajan and B. Nagalingam, "Studies on dual fuel operation of rubber seed oil and its bio-diesel with hydrogen as the inducted fuel,” Int. J. Hydrogen Energy 28, pp 1143-1154, 2003.

[10] Masood M, Ishrat MM, Reddy AS. Computational combustion and emission analysis of hydrogendiesel blends with experimental verification," Int. J. Hydrogen Energy 2007; 32: pp 2539-47.

[11] N.Sukumar Puhan, G.Vedaraman. R.Sankaranarayanan, V.Boppana.and Bharat Ram, "Performance and emission study of Mahua oil (madhuca indica oil) ethyl ester in a 4-stroke natural aspirated direct injection diesel engine," Renewable Energy 30, pp 1269-1278, 2005.

[12] C.C.M. Luijten, E. Kerkhof, "Jatropha oil and biogas In a dual fuel CI engine for rural electrification", Energy Conversion and Management 52, pp 14261438, 2011.

[13] GA Karim, "Hydrogen as a spark ignition engine fuel”, Int. J. Hydrogen Energy, 28, 2003, pp 569-77.

[14] R.Prakash, R.K.Singh, S.Murugan, "Performance and Emission Studies in a Diesel Engine Using Bio oil-Diesel Blends", 2nd International conference on environment science and technology (ICEST-2011).
[15] V.Ganesan,"A textbook on Internal Combustion Engines", 2nd edition, ISBN 0-07-049457-6, pp 220- 223.

[16] N. Saravanan, G. Nagarajan, G. Sanjay, C. Dhanasekaran, K.M. Kalaiselvan, "Combustion analysis on a DI diesel engine with hydrogen in dual fuel mode", Fuel 87, pp 3591-3599, 2008.

[17] T. Korakianitis, A M. Namasivayam, and R. J. Crookes, "Hydrogen dual-fuelling of compression Ignition engines with emulsified biodiesel as pilot fuel” Int. J. Hydrogen Energy, vol. 35, no. 24, pp. 13329-13344, Dec. 2010.

[18] B.B. Sahoo, N. Sahoo, UK. Saha, Effect of engine parameters and type of gaseous fuel on the Performance of dual-fuel gas diesel engines-A Critical review. Renewable and Sustainable Energy Reviews, 2009; 13 (6-7):1151-84.

[19] J.M.Gomes Antunes, R. Mikalsen, A.P. Roskilly, "An experimental study of a direct injection Compression ignition hydrogen engine", Int. J. Hydrogen Energy, Vol 34,pp 6516-6522,2009.

[20] M. Senthil Kumar, A. Ramesh, B. Nagalingam," Use Of hydrogen to enhance the performance of a Vegetable oil fuelled compression ignition engine," Int. J. Hydrogen Energy 28, pp 1143-1154, 2003.

[21] M. Senthil Kumar, A. Ramesh, and B. Nagalingam, "An experimental comparison of methods to use methanol and Jatropha oil in a compression ignition engine," Biomass and Bioenergy, vol. 25, no. 3, pp. 309-318, Sep. 2003.

[22] N.Saravanan, G.Nagarajan, K.M.Kalaiselvan, C.Dhanasekaran,"An experimental investigation on hydrogen as a dual fuel for engine system with Exhaust gas recirculation technique" Renewable Energy 33, pp 422-427, 2008.

[23] P. K. Bose and D. Maji, “An experimental investigation on engine performance and emissions of a single cylinder diesel engine using hydrogen as inducted fuel and diesel as injected fuel with exhaust gas recirculation," Int. J. Hydrogen Energy, vol. 34, no. 11, pp. 4847-4854, Jun. 2009.

[24] L.M. Das,'Fuel induction techniques for a hydrogen operated engine", Int. J. Hydrogen Energy, Vol.15, pp 833-842, 1990. 